\title{
Thermomechanical Behavior of Plasma-Sprayed Zirconia Thermal Barrier Coatings*
}

\author{
J. P. Singh, M. Sutaria, and A. Chopra
}

Energy Technology Division

Argonne National Laboratory

Argonne, II 60439

February 1998

The submitted manuscript has been created
by the University of Chicago as Operator of
Argonne National Laboratory ("Argonne")
under Contract No. W-31-109-ENG-38 with
the U.S. Department of Energy. The U.S.
Government retains for itsell, and others act-
ing on its behalf, a paid-up, nonexclusive,
irrevocable worldwide license in said article
to reproduce, prepare derivative works, dis-
tribute copies to the public, and perform pub-
licly and display publicty, by or on behalf of
the Government.

RECENVED

SEP 211999

OSTI

For publication in Proceedings of 22nd Annual Conference \& Exposition on Composites, Advanced Ceramics, Material and Structure, American Ceramic Society, Cocoa Beach, Florida, January 20-23, 1998.

*Research sponsored by the Office of Industrial Technologies, U.S. Department of Energy (DOE), under Contract W-31-109-Eng-38. 


\section{DISCLAIMER}

This report was prepared as an account of work sponsored by an agency of the United States Government. Neither the United States Government nor any agency thereof, nor any of their employees, make any warranty, express or implied, or assumes any legal liability or responsibility for the accuracy, completeness, or usefulness of any information, apparatus, product, or process disclosed, or represents that its use would not infringe privately owned rights. Reference herein to any specific commercial product, process, or service by trade name, trademark, manufacturer, or otherwise does not necessarily constitute or imply its endorsement, recommendation, or favoring by the United States Government or any agency thereof. The views and opinions of authors expressed herein do not necessarily state or reflect those of the United States Government or any agency thereof. 


\section{DISCLAIMER}

Portions of this document may be illegible in electronic image products. Images are produced from the best available original document. 


\title{
Thermomechanical Behavior of Plasma-Sprayed Zirconia Thermal Barrier Coatings
}

\author{
J. P. Singh, M. Sutaria, and A. Chopra
}

Energy Technology Division

Argonne National Laboratory

Argonne, IL 60439

\section{ABSTRACT}

The effect of coating porosity and thickness on the resistance to damage of yttria stabilized zirconia thermal barrier coatings in an oxidizing environment by thermal cycling was evaluated. Hardness and elastic modulus of an as-processed porous coating were lower than those of a dense coating and the porous coating failed after fewer thermal cycles. Similarly, specimen with a thicker coating failed after fewer thermal cycles than specimen with a thinner coating. The earlier failure of the porous coating is due to lower fracture toughness and enhanced oxidation of the coating/substrate interface, whereas, the earlier failure of the thick coating is due to higher thermal transient stresses that developed in the coating during thermal cycling. Generally, an increase in coating density led to initial increase in both hardness and elastic modulus with increasing thermal cycles. However, hardness and density gradually decreased as the number of thermal cycles increase because of microcracks formation and growth. Microscopic observations indicated that the formation of multiple microcracks and their subsequent growth and coalescence led to final coating failure.

\section{INTRODUCTION}

Thermal barrier coatings (TBCs) have shown great potential for increasing turbine inlet-gas temperature by reducing heat transfer from the hot gas to air-cooled blades. Turbine superalloys melt in the range of $1230-1315^{\circ} \mathrm{C}$ [1]. Because the combustion gas environment is at $\approx 1370^{\circ} \mathrm{C}$, the superalloys are air cooled to protect them from the oxidation, creep, melting, and thermal fatigue that reduce efficiency. Traditionally, efficiency is improved by improving the design of the cooling system. An alternative is to use TBCs. A typical TBC system consists of an insulating outer ceramic layer and an inner metallic "bond coat" layer between the ceramic layer and the metallic substrate. TBCs improve performance and increase efficiency by lowering the turbine temperature and reducing the cooling-air requirements [2-4].

Premature failure of the ceramic coating layer, a concern when reliability and long service life of gas turbine components are considered [5-7], may be related to factors such as residual stresses that develop in the ceramic layer during cooling because of expansion mismatch between the ceramic and metallic layers [5-9]; cyclic inelastic strain in the coating due to thermal cycling during service [10-11]; oxidation, plastic deformation and creep of the bond layer; and phase transformation and sintering of the top layer. Therefore, it is critical that we understand the effects of these parameters on coating failure if we are to predict performance and service life of TBCs. Many of these parameters, such as residual stresses, elastic and inelastic strains during thermal 
made to obtain a statistically reliable value. Subsequently, the surface was fine-polished and Knoop indentations were made at the same locations and identical loads and times were used to evaluate elastic modulus. The Knoop indentation diagonals ( $b^{\prime}$ and $\left.a^{\prime}\right)$, shown in Fig. 2, were carefully measured with a high-magnification optical microscope. With a known value of $a / b$ (7.11) for the Knoop indenter geometry, elastic recovery ( $\left.b^{\prime} / a^{\prime}-b / a\right)$ was evaluated, and elastic moduli were calculated from Eq. 2.

$$
\frac{b^{\prime}}{a^{\prime}}=\frac{b^{\prime}}{a^{\prime}}-\alpha \frac{H}{E} .
$$

\section{RESULTS AND DISCUSSION}

Figure 3 shows the variation of hardness and elastic modulus for the two specimens with differing porosity (Set A), as a function of thermal cycles. As shown in the figure, both hardness and elastic modulus values of the specimen with a porous coating are lower than those of the specimen with a dense coating. The hardness and elastic modulus values of the dense coating specimen in as-received condition are $\approx 8$ and $\approx 85 \mathrm{GPa}$, respectively. The corresponding values for the porous coating specimen are $\approx 5$ and $\approx 60 \mathrm{GPa}$, respectively. The lower values for the porous specimen are the result of higher porosity, which caused the coating to fail (spall from the substrate) after only 10 thermal cycles. On the other hand, the specimen with a dense coating did not fail, even after 25 cycles. Failure of the porous coating after only a small number of cycles is partly due to the low fracture toughness of the coating. Furthermore, higher porosity may also have caused higher oxidation at the substrate/coating interface, which led to premature failure. The exact cause of premature failure is currently under investigation.

As seen in Fig. 3, the elastic modulus of the dense coating initially increased with an increasing number of thermal cycles and reached a maximum of $\approx 110 \mathrm{GPa}$ at 10 cycles. Further increase in cycles resulted in a corresponding decrease in elastic modulus. In general, hardness variation showed the similar trend. We believe that the initial increase in elastic modulus is the result of an increase in coating density. For example, if the coating specimen had been exposed to $1150^{\circ} \mathrm{C}$ for $10 \mathrm{~h}$ after 10 cycles, the density would be expected to increase. Because elastic modulus is inversely proportional to porosity, increased density led to a higher elastic modulus. However, at higher thermal cycles, more microcracks were formed and growth of pre-existing cracks was observed. As noted by Hasselman and Singh [13], elastic modulus is strongly dependent on and varies inversely with increasing crack length and density. This effect becomes more dominant than densification as the number of thermal cycles increases and leads to a net decrease in elastic modulus.

Figure 4 shows the variation of hardness and elastic modulus of the two specimens with coatings of differing thickness (Specimen Set B) as a function of thermal cycles. As shown in the figure, both the hardness and elastic modulus of the thicker coating $(540 \mu \mathrm{m})$ were lower than those of the thinner coating $(340 \mu \mathrm{m})$ and failed after fewer thermal cycles. Both hardness and elastic modulus initially increase with an increasing number of thermal cycles and subsequently decrease at higher number of cycles. As discussed in the previous paragraph, this behavior is the result of an increase in coating density during the initial thermal cycles and of microcrack formation and growth 


\section{REFERENCES}

1. S. M. Meier and D. K. Gupta, "The Evolution of Thermal Barrier Coatings in Gas Turbine Applications," J. Engineering for Gas Turbine and Power, Trans. ASME, 111, 301-305, 1989.

2. D. L. Ruckle, "Plasma Sprayed Ceramic Coatings for Turbine Vane Platforms," Thin Solid Films, 73, 455, 1980.

3. R. A. Miller, S. R. Levine, and S. Stecura, "Thermal Barrier Coatings for Aircraft Gas Turbines," AIAA Paper No. 80-0302, 1980.

4. D. S. Duvall and D. L. Ruckle, "Ceramic Thermal Barrier Coatings for Turbine Engine Components," ASME Paper No. 82-GT-332, 1982.

5. R. A. Miller and C. E. Lowell, "Failure Mechanisms of Thermal Barrier Coatings Exposed to Elevated Temperature," Thin Solid Films, 99, 265, 1982.

6. S. J. Grisaffe and S. R. Levine, Proceedings of the First DOE/EPRI Conference on Advanced Materials for Alternate Fuel Capable Directly Fired Heat Engines, Castine, ME, 1979.

7. D. L. Ruckle, "Evaluation of Plasma Sprayed Ceramic Coatings for Turbine Engine Components," Thin Solid Films, 64, 327, 1979.

8. P. F. Becher, R. W. Rice, C. C. Wu, and R. L. Jones, "Factors in the Degradation of Ceramic Coatings for Turbine Alloys," Thin Solid Films, 53, 225, 1978.

9. S. Rangaswamy and H. Herman, "Thermal Expansion Study of Plasma-Sprayed Oxide Coatings," Thin Solid Films, 73, 43, 1980.

10. J. T. DeMasi-Marcin, K. D. Sheffler, and S. Bose, "Mechanisms of Degradation and Failure in a Plasma-Deposited Thermal Barrier Coating," ASME Journal of Engineering for Gas Turbines and Power, 112, 521-526, 1990.

11. "Thermal Barrier Coating Life Prediction Model Development-Final Report, No. NASA CR-180807," Performed by General Electric Co., Cincinnati, OH; Sponsored by National Aeronautics and Space Administration, Lewis Research Center, Cleveland, OH, Nov. 1988.

12. J. P. Singh, M. Sutaria, and M. Ferber, "Use of Indentation Technique to Measure Elastic Modulus of Plasma-Sprayed Zirconia Thermal Barrier Coating," Ceram. Eng. Sci. Proc., 18(4) 191-200, 1997.

13. D. P. H. Hasselman and J. P. Singh, "Analysis of Thermal Stress Resistance of Microcracked Brittle Ceramics," Ceramic Bulletin, 58(9), 856-60, 1979.

14. J. C. Jaeger "On Thermal Stresses on Circular Cylinders," Philos. Mag., 36, 418-27, 1945. 


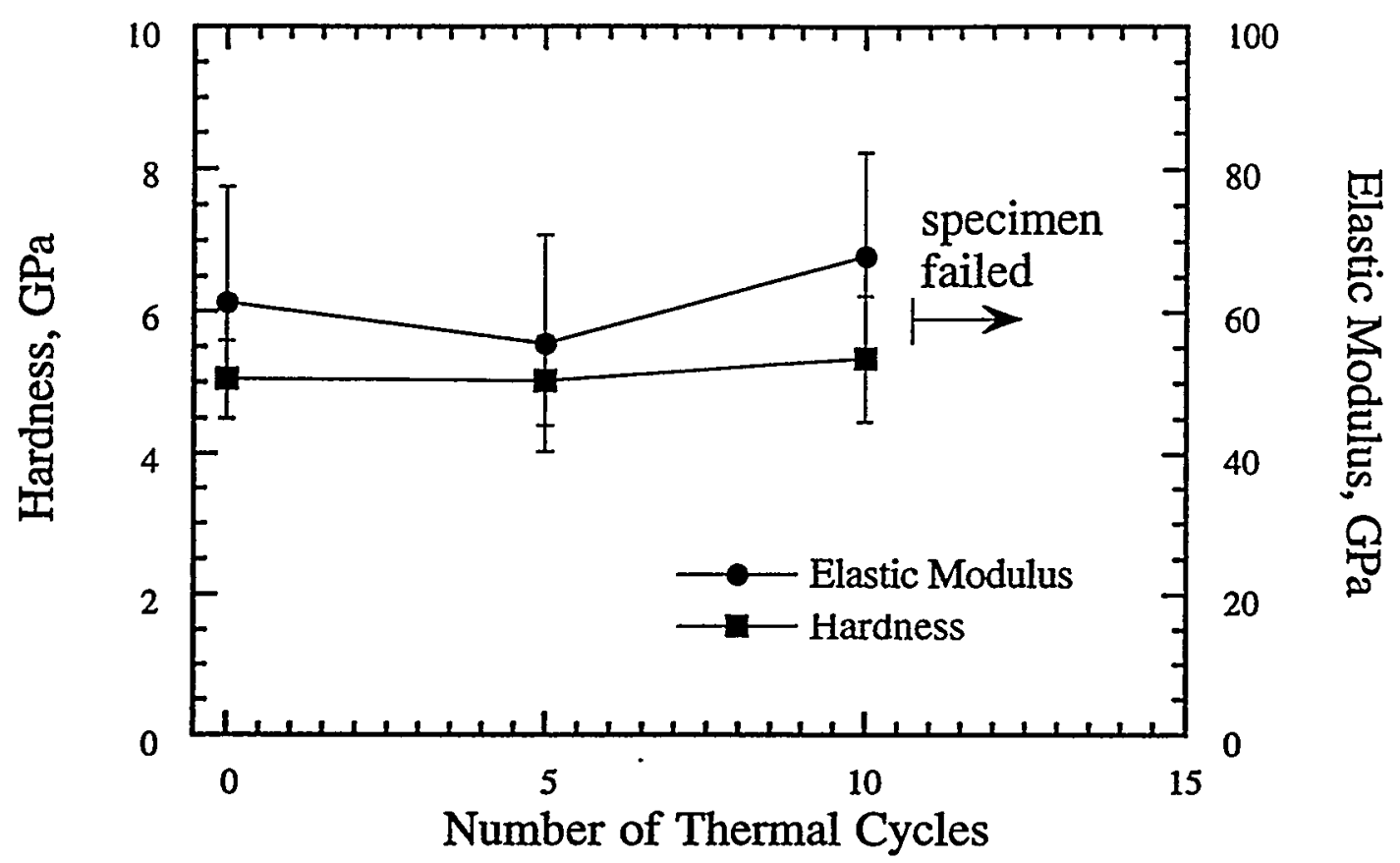

(a)

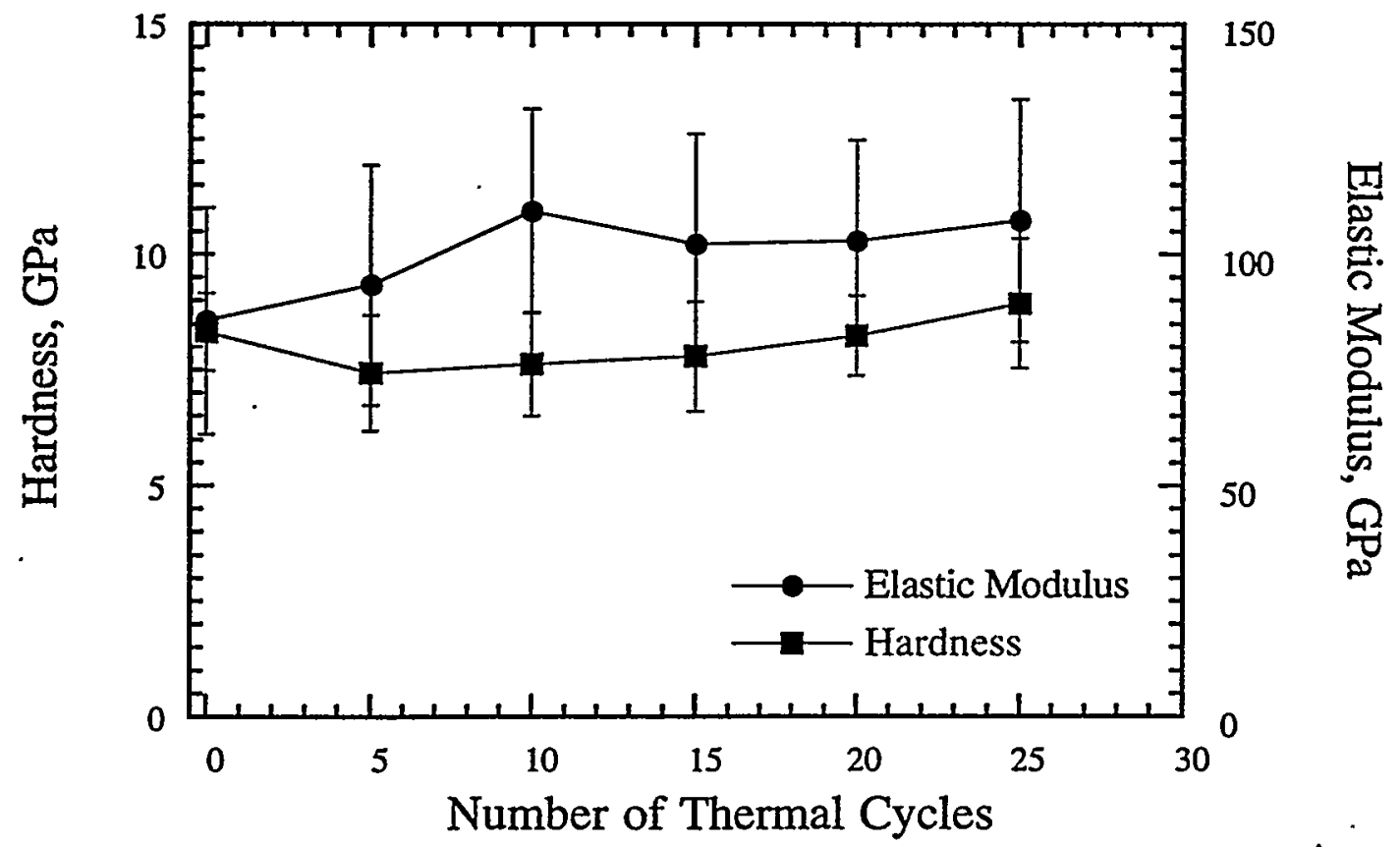

(b)

Fig. 3. Hardness and elastic modulus variation of specimen with (a) porous and (b) dense coating. 


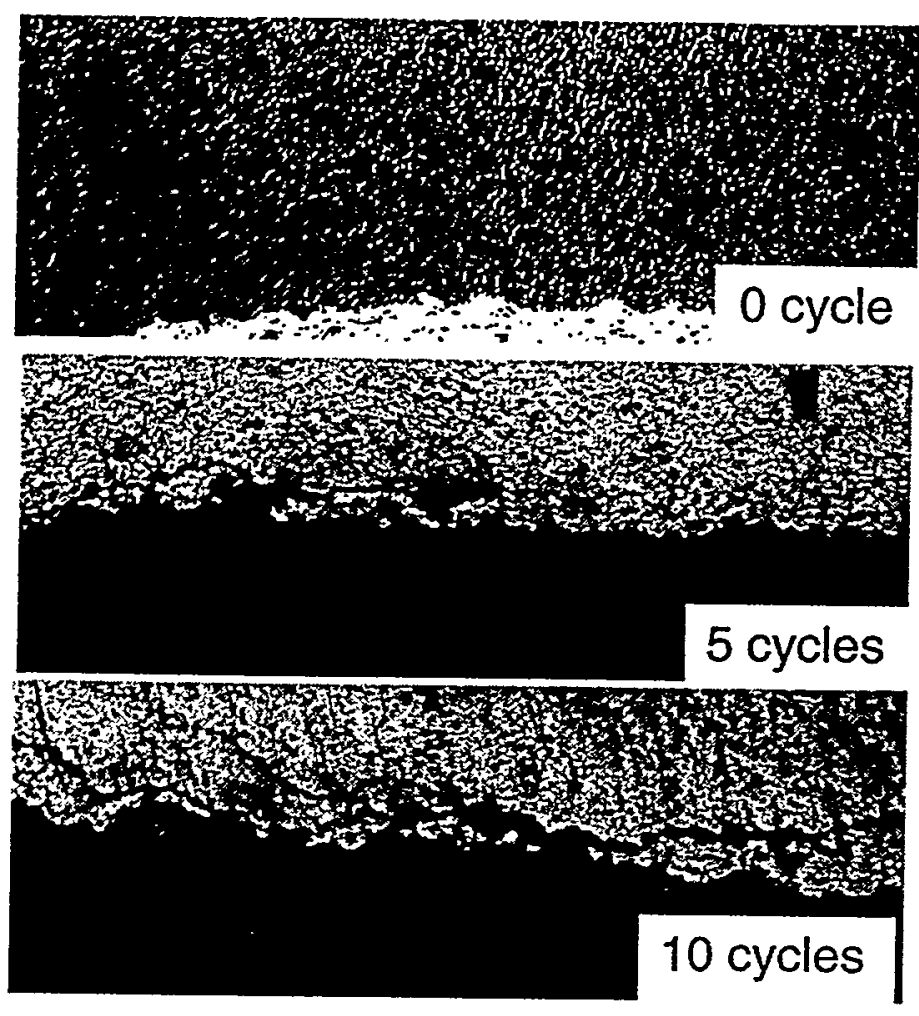

Fig. 5. Photo micrographs showing crack propagation in top coat as a function of thermal cycles. 